Original articles

J. Perinat. Med. 17 (1989) 77

\title{
Clinical outcome of small for gestational age preterm infants
}

\author{
Isabelle Ruys-Dudok van Heel and Richard de Leeuw \\ Department of Neonatology, Academic Medical Center, Amsterdam, The Nether- \\ lands
}

\section{Introduction}

The clinical performance of the SGA (Small for Gestational Age) preterm infant is a point of controversy. Some authors report a favorable outcome for the SGA preterm infant in comparison to an AGA (Appropriate for Gestational Age) preterm infant $[1-3]$. These studies describe birthweight defined populations. It is obviously true that a child of 900 grams and 32 weeks of gestation has a lower mortality risk than an AGA infant of 900 grams and 27 weeks of gestation. Other studies reported that intra uterine growth retardation was associated with poor neonatal outcome [4-6].

In the present study we retrospectively compared a population of preterm SGA infants to a population of AGA infants matched for gestational age and sex. A comparable study was done by HeINoNEN [4]. The neonatal outcome of SGA preterm infants is of special interest for the neonatologist as well as for the obstetrician. Most of the SGA preterm infants in this study were delivered by caesarean section. It can be very difficult to decide when to deliver the preterm pregnancy in case of fetal distress. The morbidity and mortality risks of the growth retarded fetus need to be considered in relation to the risks of the SGA preterm newborn after delivery.

\section{Patients and methods}

The data of 110 preterm infants with a gestational age ranging from 29 to 37 weeks (calculated on the basis of the mothers last menstrual period and corrected by early ultrasound) were reviewed retrospectively. In the 5 year period $1981-1986,1585$ preterm children were admitted to the neonatology

\section{Curriculum vitae}

ISABELLE RUYS-DUDOK VAN HEEL, M. D., was born in 1957 in the Netherlands, and attended Medical School at the University of Leiden from 1975-1983. This was followed by a one year's surgical rotation. Her pedriatic residency was in Amsterdam (19841988). She worked in a genetic research laboratory in

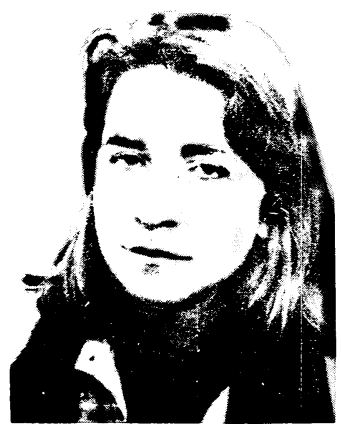

New York for seven months. In June 1988 she started work in the Department of Neonatology of the Academic Hospital of the University of Amsterdam.

department of The Academic Hospital of the University of Amsterdam. Excluding twin infants, fifty five infants were born with a birthweight below the 2.3rd percentile for gestational age according to the Amsterdam growth charts (Kloosterman 1970) [7].

For each SGA child a control AGA child matched for gestational age and sex, born shortly after the SGA child was identified. The birthweights of the children of the AGA group ranged from the 25th to the 75th percentile for gestational age. Eleven of the SGA children were transferred to our hospital. For those children, controls were found that were also transferred. All other infants were born in the department of obstetrics of the Academical Hospital of the University of Amsterdam.

For statistical analyses the $\mathrm{X}^{2}$ analysis was used. The infants were seen for follow-up study at 1,3 , 
6, 9 and 12 months and in most cases at 18, 24 and 30 months after discharge of the hospital. Developmental screening was performed according to tests described by Egan, Illingworth and Mac Keith [8].

\section{Results}

The results are summarized in the table.

\subsection{Pregnancy and delivery}

The pregnancies of 32 mothers of SGA infants were complicated by hypertension with a diastolic blood pressure above $90 \mathrm{mmHg}$. Forty seven SGA infants and 13 AGA infants demonstrated signs of fetal distress by cardiotocography and 45 SGA infants and 12 AGA infants were delivered by caesarean section.

Table. Clinical and flollow-up data of both groups of infants.

\begin{tabular}{lll}
\hline & 55 & 55 \\
& S.G.A. & A.G.A.
\end{tabular}

\section{Pregnancy}

- hypertension

- prolonged ruptured

$32 *$ membranes

\section{Delivery}

- Caesarean section

45

\section{Respiratory problems}
A - Apgar score $<7$ at $1^{\prime}$
- Apgar score $<7$ at $5^{\prime}$
- asphyxic syndrome
B - transient tachypnoe of the newborn
- hyaline membrane disease
$\mathrm{C}$ - apneas

\section{Circulatory problems}

- persistent ductus arteriosus

\section{Gastrointestinal problems}

- vomiting, gastric problems

- distented abdomen (functional ileus)

- necrotising enterocolitis

- cholestatic icterus

- parental nutrition $>1$ week
Figure 1 shows the distribution of birthweights in boths groups. Figure 2 shows the distribution of gestational age in weeks.

\subsection{Respiratory problems}

An Apgar score below 7 at 1 or 5 minutes may be considered as an indication of perinatal hypoxia (table). The asphyxia syndrome is defined as signs of respiratory distress, without signs of hyaline membrane disease (HMD) in an infant that was asphyxiated at birth. This syndrome is sometimes accompanied by cerebral and/or nephrological problems.

The difference in incidence of HMD between the two groups was not significant. There was a difference in severity of the HMD. Of 10 SGA infants who developed HMD, all required mechanical ventilation with 7 deaths. Of 15 AGA infants with

Table. Continued.

\begin{tabular}{lll}
\hline & 55 & 55 \\
& S.G.A. & A.G.A. \\
\hline $\begin{array}{l}\text { Bacteriology } \\
-\quad \begin{array}{l}\text { major infections (sepsis, } \\
\text { meningitis, pneumonia) }\end{array}\end{array}$ & 17 & 10 \\
$-\begin{array}{l}\text { minor infections (umbili- } \\
\text { cus, skin, conjuntiva) }\end{array}$ & $27^{*}$ & 9
\end{tabular}

\section{Hematology}

- normoblastosis $(>20 \%) \quad 37^{*} \quad 5$

- leucopenia $\left(<4 \times 10^{9} / \mathrm{L}\right) \quad 25^{*} \quad 2$

- thrombocytopenia $37^{*} \quad 6$

$$
\left(<100 \times 10^{9} / \mathrm{L}\right)
$$

- polycythemia $(\mathrm{Ht}>65 \%) \quad 7 \quad 5$

\section{Intracranial hemorrhage}

- ultrasound obtained in $\quad 40$ patients number

$40 \quad 28$

- subependymal hemorrhage 44

- intraventricular

$4(2 \dagger) \quad 4(1 \dagger)$ hemorrhage

- parenchymal hemorrhage

\section{Psychological and motor development}

\begin{tabular}{lcc} 
- normal & 34 & 44 \\
- retardation & 8 & 4 \\
- follow-up shorter than 1 & $13(12 \dagger)$ & $7(4 \dagger)$ \\
$\quad$ year & \\
\hline * statistical differences between the two groups. \\
$(P<0.05)$
\end{tabular}



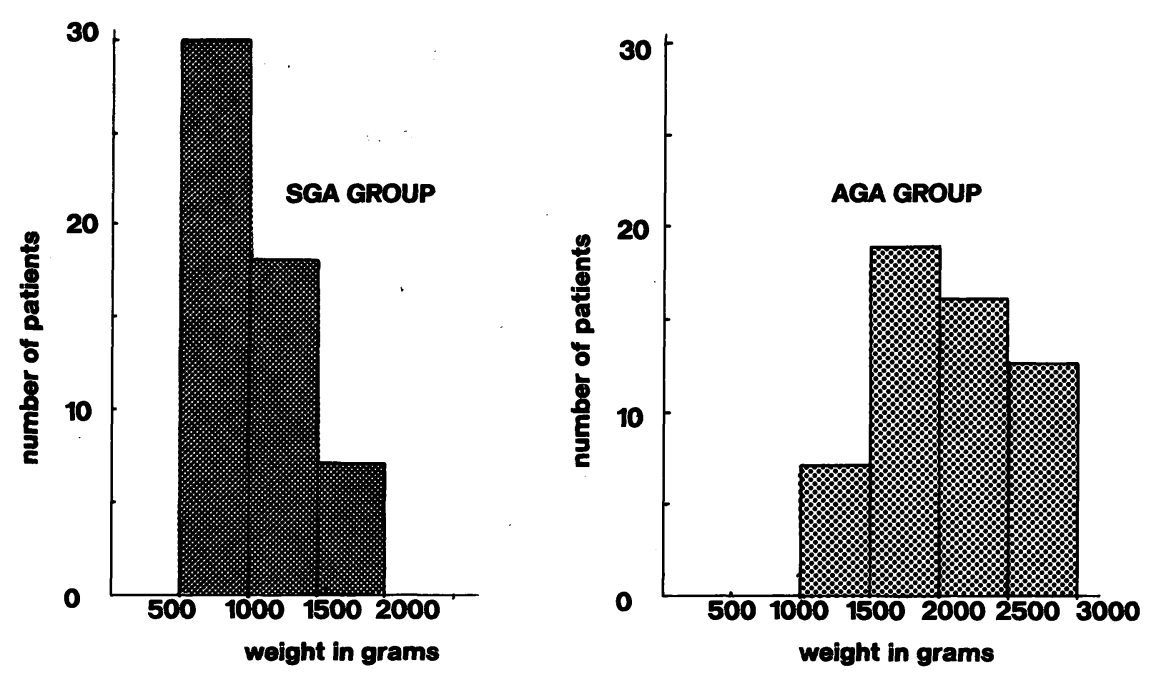

Figure 1. Birth weights of both groups of patients shown in 2 diagrams.

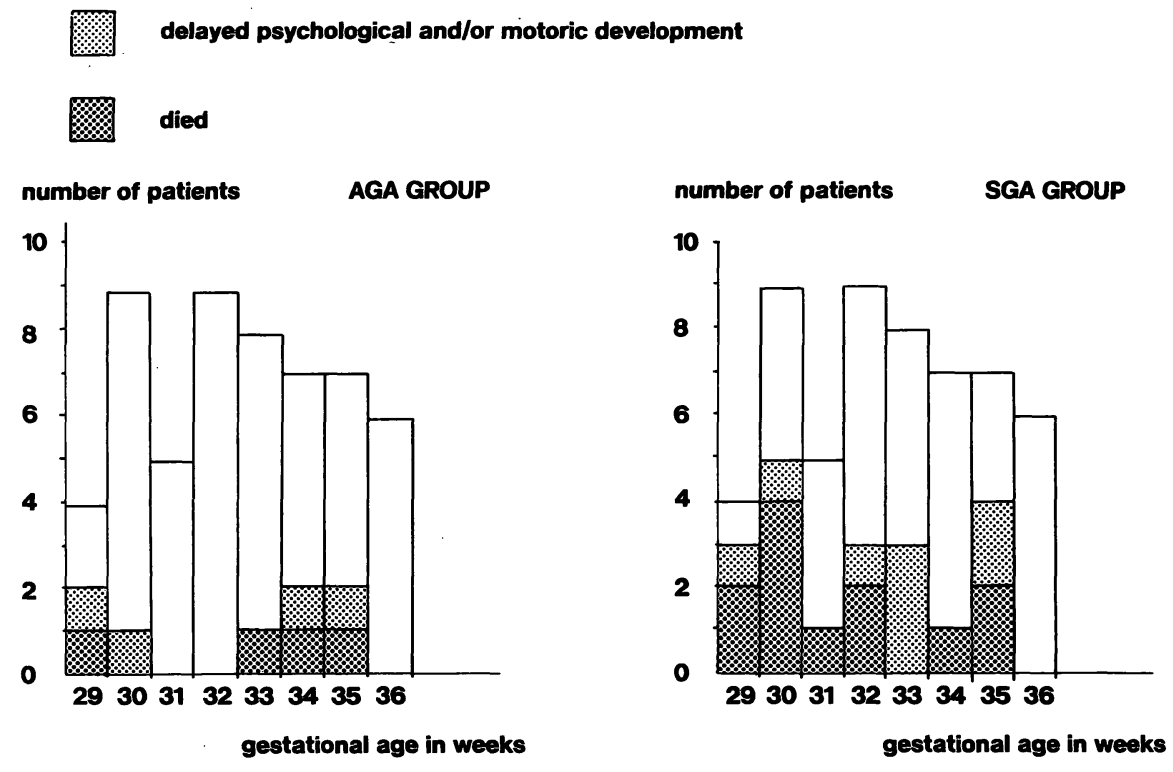

Figure 2. The 2 patient groups divided on the basis of their gestational age in weeks. The patients that died or that are handicapped are marked.

HMD, 7 needed mechanical ventilation with only one death. Mortality caused by HMD was significantly higher in the SGA group.

\subsection{Circulatory problems}

A persistent ductus arteriosus was suspected from clinical findings, and the diagnosis was confirmed by a left atrium-aorta ratio $>1$ detected by echocardiography (table).

\subsection{Gastrointestinal problems}

There were major differences in the incidence of gastrointestinal problems between the 2 groups. This was reflected by the use of parenteral nutri- 
tion (table). Electrolyte disturbances (potassium $<3.5 \mathrm{mmol} / \mathrm{L}$ or $>6.5 \mathrm{mmol} / \mathrm{L}$, calcium $<1.75$ $\mathrm{mmol} / \mathrm{L}$, sodium $<130 \mathrm{mmol} / \mathrm{L}$ or $>150$ $\mathrm{mmol} / \mathrm{L})$, hypertriglyceridemias $(>150 \mathrm{mmol} / \mathrm{L})$, hyperglycemias (glucose $>7 \mathrm{mmol} / \mathrm{L}$ ) and hypoglycemias $(<1.1 \mathrm{mmol} / \mathrm{L}$ in the first 48 hours after birth and $<1.7 \mathrm{mmol} / \mathrm{L}$ after that time) were all significantly more frequent in the SGA group. Cholestatic jaundice is defined as a jaundice occurring later in life than the physiological jaundice, with an elevated conjugated bilirubin and elevated serum transaminases.

\subsection{Bacteriology}

Only minor infections were significantly more frequent in the SGA group (table).

Of the 15 septicemias in the SGA group and the 7 septicemias in the AGA group only 5 and 1 respectively were confirmed by positive blood cultures. The other septicemias were diagnosed on clinical criteria only.

\subsection{Hematological disturbances}

These were more frequently seen in the SGA group than in the AGA group (table).

\subsection{Cranial ultrasound}

Since a cranial ultrasound at that time was not always performed as a routine procedure, it was obtained in 40 SGA and 28 AGA infants. There was no significant difference in the incidence of intracranial hemorrhages between the two groups. Two children who died with extensive bleeding in the brain parenchyma were in the SGA group.

\subsection{Bilirubin concentration}

The mean maximum serum bilirubin concentration was significantly lower in the SGA group (157 $\mu \mathrm{mol} / \mathrm{L}, \mathrm{SD} 42)$ than in the AGA group (211 $\mu \mathrm{mol} / \mathrm{L}, \mathrm{SD} 41)$.

\subsection{Congenital malformations}

One child of the SGA group had an extra piece of $\mathrm{Y}$ chromatin on both chromosomes 22. This translocation has no known clinical influence [9]. In the AGA group there was one child with achon- droplasia and tricuspid atresia. This child died at the age of seven months. One child in the SGA group had a small AV-septum defect without clinical problems during the neonatal period. Two children in the SGA group had hypospadias, one had ambiguous genitalia. One AGA child had a syndactyly. One child of the AGA group died of a meningomyelocele.

\subsection{Mortality}

Mortality was $21.8 \%$ in the SGA group compared to $7.2 \%$ in the AGA group (significant): In figure 2 mortality in both groups is shown.

\subsection{Psychological and motor development}

Out of 8 developmentally delayed SGA children two are severely handicapped, one of 4 retarded AGA children is severely affected. Considering only the children in whom a follow up longer than one year was possible (42 SGA: 12 died, 1 no follow up $>1$ year and 48 AGA: 4 died, 3 no follow up $>1$ year), the percentages of handicapped children are $19 \%$ in the SGA group and $9 \%$ in the AGA group. The percentages of severe handicaps are $4.8 \%$ and $2.3 \%$ respectively.

The minor handicaps were slow psychological or motor development. One severely handicapped SGA child has spastic paraplegia, one has a severe retardation and frequent epileptic insults. The severely handicapped AGA child had progressive hydrocephalus, a disturbed vision and is mentally retarded. In figure 2 handicapped infants are marked in both groups, divided according to gestational age.

\section{Discussion}

The majority of SGA infants are born at or near term [10]. SGA infants form a heterogenous group, since their intrauterine growth retardation can have different etiologies. The intrauterine growth retardation of the preterm infants described in this study must have begun very early in the pregnancy. We have chosen the very small for gestational age premature infants (birthweight $\mathrm{P}<2.3$ for gestational age) to see whether their intrauterine growth retardation placed them at a greater risk than gestational age matched control infants with normal intrauterine growth. 
These infants may have suffered severe stress (malnutrition, hypoxia) in utero. In addition to the intrauterine stress they were born preterm, often by caesarean section. The combination of stress and immaturity resulted in the adverse clinical findings.

The immaturity of the lungs is reflected by the deficiency of production of surfactant causing HMD in these infants. When the child is under prolonged stress in utero one would expect an accelerated maturation of the lungs because of endogenous corticosteroid production [11]. In very severe intrauterine hypoxia this effect is probably lost [12]. This hypothesis is reflected in our SGA population, since we found fewer children affected by HMD compared to the control group. (This difference in incidence was not significant.) The SGA children with the diagnosis HMD suffered from a very severe type of HMD. They all had to be ventilated mechanically, and 7 out of these 10 infants died.

Often hypoxia had already begun in utero in the SGA infant and accordingly significantly more perinatal hypoxia in the SGA group could be expected. Three infants died as a direct result of the asphyxia.

The digestive tract is also influenced by a combination of effects caused by immaturity and stress in utero. The former results in the small capacity of the stomach, the diminished peristalsis and the impaired digestion [13]. The intrauterine malnutrition may cause mucosal atrophy and hypoxia may cause ischemia of the bowel. Stasis in this vulnerable bowel can cause necrotising enterocolitis, sepsis or even perforation of the bowel. Malnutrition starts in utero, but since the bowel is not in a good condition to digest nutrients properly, malnutrition continues after birth. Total I. V. nutrition is certainly not without risks. It appears that the AGA premature infant metabolises the I. V. nutrition better than the SGA premature [14]

Cholestasis, as was often seen in the SGA group, is probably the result of both stasis in the digestive tract which occurs in these infants and the longstanding I. V. nutrition [15].

All preterm infants are prone to infection, but it seems that SGA infants are especially at risk. Only minor infections were seen significantly more often, but these can lead to major infections. In SGA infants born at term lower IgG values and lower $\mathrm{C}_{3}$ complement values have been described in comparison with AGA term newborns [16].
Cell mediated immunity in term SGA children is impaired $[17,18]$. These factors have not yet been studied in SGA infants born preterm.

Hematological disturbances such as normoblastosis (37 SGA vs. 5 AGA), leucopenia (25 SGA vs. 2 AGA) and thrombocytopenia (37 SGA vs. 6 AGA) are found significantly more often in the SGA group. Probably as a result of intrauterine hypoxia, the bone marrow is stimulated to increase its red cell production. The production of white cells and platelets is depressed as a result of this. The thrombocytopenia which was severe $(<20 \times$ $10^{9} / \mathrm{L}$ ) in $5 \mathrm{SGA}$ infants increases the susceptibility to intracranial hemorrhage and the leucopenia increases the susceptibility for infection.

The significantly lower maximum bilirubin values in the SGA group might be a reflection of an accelerated maturation of the liver due to intrauterine stress. To our knowledge this has not been described before.

We could find no significant difference in the incidence of intracranial hemorrhages, but Heinonen et al found significantly more cases with fatal intraventricular hemorrhages in preterm SGA infants than in preterm AGA infants [4]. A cranial ultrasound was obtained in 40 SGA and 28 AGA infants. The only large hemorrhages in the cerebral parenchyma in our study were found in 2 SGA infants, and were both fatal.

Term SGA children are at greater risk for neurological problems and developmental handicaps than their AGA controls [19]. Concerning SGA preterm infants the incidence of handicaps varies from $10-50 \%$ [19-22].

In the present study mortality was significantly higher in the SGA group.

In figure 2 the patient groups are shown divided on the basis of their gestational age in weeks. Those that died and those who are handicapped are marked. Mortality rate is highest as expected in the younger age group. One cannot be sure how many children would be handicapped, if, with the steadily improving medical care, also those children of 29 and 30 weeks will be kept alive. On the other hand one also wonders if the handicaps in the older age group could have been avoided if a caesarean section had been planned at an earlier time in pregnancy. 


\section{Conclusion}

Reviewing all these data we can conclude that SGA preterm infants do worse in many aspects compared to their AGA controls. Especially in the younger gestational age group the results are poor. One has to bear in mind that most of the SGA children were born by caesarean section. We do not pretend to be able to tell the obstetrician, on the basis of the data presented in this study, pre- cisely when a severely growth retarded child should be delivered. If pregnancy had been terminated earlier we certainly would have been confronted with more problems related to immaturity. But perhaps in some cases earlier termination may have prevented cerebral injury caused by intrauterine stress.

Further studies will be needed to help solve this problems.

\begin{abstract}
Data from 55 preterm SGA infants and 55 preterm AGA infants matched for gestational age and sex were reviewed retrospectively. An increased incidence of perinatal hypoxia ( 30 vs. 18 ), gastrointestinal problems, minor infections (27 vs. 9), hematological problems and increased mortality $(21.8 \%$ vs. $7.2 \%)$ was observed in the SGA infants.
\end{abstract}

The incidence of HMD was higher in the AGA group (not significant), but the HMD was much more severe in the SGA group. Mortality as a result of HMD was significantly higher in the SGA group. The percentage

Keywords: Preterm, small for gestational age.

\section{Zusammenfassung}

Klinischer Verlauf bei Small for date-Frühgeborenen

Retrospektiv untersuchten wir die Daten von 55 Small for date-Frühgeborenen (SGA-Gruppe) und 55 Frühgeborenen mit adäquatem Geburtsgewicht (AGAGruppe) nach Zuordnung bezüglich des Gestationsalters und des Geschlechts.

In der SGA-Gruppe beobachteten wir eine erhöhte Inzidenz von perinatalen Hypoxien (30 vs. 18), gastrointestinalen Problemen, geringfügigen Infektionen (27 vs. 9) und hämatologischen Problemen sowie eine erhöhte Mortalität $(21.8 \%$ vs. $7.2 \%)$.

Ein Atemnotsyndrom trat in der AGA-Gruppe häufiger auf (nicht signifikant), jedoch war dieses Syndrom in der SGA-Gruppe sehr viel stärker ausgeprägt. Die Morta-

Schlüsselwörter: Frühgeburt, Small for date.

\section{Résumé}

Comportement clinique des enfants hypotrophes prématurés

On a analysé rétrospectivement les données concernant 55 enfants prématurés hypotrophes (SGA) et 55 enfants prématurés normotrophes (AGA) apariés pour l'âge gestationnel et le sexe. of handicapped children is $19 \%$ in the SGA group and $9 \%$ in the AGA group. The percentages of severely handicapped children are $4.8 \%$ and $2.3 \%$ respectively.

The combination of prematurity and severe intrauterine growth retardation in the SGA group caused a higher mortality and morbidity than was seen in their AGA controls.

This clinical performance of SGA preterm infants is important especially for those who have to decide at what moment such a child should be delivered by caesarean section.

lität in Folge des Atemnotsyndroms war in der SGAGruppe signifikant höher. Der Anteil der Kinder mit geringen Beeinträchtigungen betrug in der SGA-Gruppe $19 \%$ und in der AGA-Gruppe 9\%; schwere Beeinträchtigungen fanden sich in $4.8 \%$ bzw. $2.3 \%$.

Die Kombination von Frühgeburtlichkeit und schwerer intrauteriner Wachstumsretardierung resultierte in einer im Vergleich zu den AGA-Kontrollen höheren Mortalität und Morbidität.

Die klinischen Verläufe bei SGA-Frühgeborenen bzw. deren Kenntnis sind von besonderer Bedeutung für diejenigen, die zu entscheiden haben, wann ein Kinder per Sectio entbunden werden sollte.

On a observé une incidence accrue chez les enfants SGA d'hypoxie périnatale ( 30 vs 18 ), de problèmes gastrointestinaux, d'infections mineures (27 vs 9$)$, de problèmes hématologiques ainsi qu'une mortalité plus élevée $(21,8 \%$ vs $7,2 \%)$. 
L'incisence d'HMD est plus élevée dans le groupe AGA (non significatif), mais l'HMD est plus grave dans le groupe SGA. La mortalité provoquée par HMD est significativement plus élevée dans le groupe SGA. Le pourcentage d'enfants handicapés est de $19 \%$ dans le groupe SGA et de $9 \%$ dans le groupe AGA. Le pourcentage d'enfants lourdement handicapés est de $4,8 \%$ et de $2,3 \%$ respectivement.

Mots-clés: Hypotrophie, prématuré.

\section{References}

[1] Hoskins EM, E Elliot, AT Shennan, MB SkIDMORE, E KEITH: Outcome of very low-birth weight infants born at a perinatal center. Am J Obstet Gynecol (1983) 135

[2] Goldenberg RL, KG Nelson, JF Koski, GR CuTLER: Low birth weight, intrauterine growth retardation and preterm delivery. Am J Obstet Gynecol (1985) 980

[3] Yu VYH, L Downe, J AstbuRy, B BaJuk: Perinatal factors and adverse outcome in extremely low birthweights infants. Arch dis Child (1986) 554

[4] Heinonen K, R Matilainen, H Koski, K LauniALA: Intra-uterine growth retardation in preterm infants. J perinat Med (1985) 171

[5] Verloove SP, RA VerweY: Project on preterm and small for gestational age infants in the Netherlands 1983. A collaborative survey. Thesis in Leiden, The Netherlands 1987.

[6] FitZHARDINGE PM: Intrauterine growth retardation. An added risk to the preterm infant. Presented at the International Neonatal Intensive Care Conference at Durham, New Hampshire 1977.

[7] KLoosterman GJ: On intrauterine fetal grown. The significance of prenatal care. Int J Gynaec Obstet (1970) 895

[8] Egan DF, RS Illingworth, RC MaC KeIth: Developmental screening $0-5$ years. London. Spastics International Medical Publications in association with William Heinemann Medical Books Ltd 1969.

[9] LESCHOT NJ: Homozygocity for an Y-22 chromosome translocation: $\mathrm{T}(\mathrm{Y} ; 22)(\mathrm{Q} 12 ; \mathrm{P} 12 / 13)$. Clin Genet (1986) 251

[10] Klaus MH, AA FanarofF: Care of the high-risk neonate. W. B. Sanders Company. Third Edition 1986

[11] GLuCK L, MV KuLOVICH: Lecithin/sphinogomyelin ratios in amniotic fluid in normal and abnormal pregnancy. Am J Obst Gynaec (1973) 539

[12] MerRitT TA, PM FARRELL: Diminished pulmonary lecithin synthesis in acidosis: Experimental findings as related to the respiratory distress syndrome. Pediatrics (1976) 32.
L'association de la prématurité et du retard de croissance sévère dans le groupe SGA entraîne une mortalité et une morbidité plus élevées que celles observées dans leurs rémoins AGA.

Ce comportement clinique des enfants prématurés AGA est important tout particulièrement pour ceux qui ont à décider à quel moment de tels enfants doivent naître par césarienne.

[13] Lebenthal E, PC Lee, PA Heitlinger: Impact of development of the gastrointestinal tract in infant feeding. J Pediatr (1983) 1

[14] Lindblad BS, G Stettergren, H Feychting, B PERSSON: Total parenteral nutrition in infants. Acta Pediatr Scand (1977) 409

[15] Fatrell MK, WF BalistiERI: Parenteral nutrition and hepatobiliary dysfunction. Clin Perinatol (1986) 197

[16] Shapiro R, DW Beatty, DL Woods at al: Serum complement and immunoglobulin values in small for gestational age infants. J Pediatr (1981) 139

[17] ChANDRA RK: Impairment of immunity in children with intra-uterine growth retardation. J Pediatr (1979) 157

[18] ChANDRA RK: Serum thymic hormone activity and cell-mediated immunity in healthy neonates, preterm infants and small for gestational age infants. Pediatrics (1981) 407

[19] Allen MC: Developmental outcome and follow up of the small for gestational age infant. Semin. Perinatol. (1984) 123-156

[20] Vohr BR, W OH, AG Rosenfield, ET AL: The preterm small for gestational age infant: a two year follow up study. Am J Obstet Gynecol (1979) 425

[21] Fitzhardinge PM, E Kalman, S Ashly et al: Present status of the infant of very low birth weight treated in a referral neonatal intensive care unit in 1974. New York, Exerpta Medica. CIBA Foundation Symposium 1979

[22] Commey JO, PM Fitzhardinge: Handicap in the preterm for gestational age infant. J Pediatr (1979) 779

Received June 23, 1988. Revised December 27, 1988. Accepted January 6, 1989.

Isabelle Ruys-Dudok van Heel M.D.

Department of Neonatology

Academic Medical Center

Meibergdreef 9

1105 AZ Amsterdam

The Netherlands 